\title{
FINANCIAL TECHNOLOGY (FINTECH) DI INDONESIA DITINJAU DARI PERSPEKTIF ISLAM
}

\author{
Maulidah Narastri ${ }^{1}$ \\ Universitas 17 Agustus 1945 Surabaya, Indonesia \\ maulidah@untag-sby.ac.id isti@steikassi.ac.id
}

\author{
Abdullah Kafabih 2 \\ Universitas Islam Sunan Ampel Surabaya, Indonesia \\ abdullahkafabih@uinsby.ac.id
}

\begin{abstract}
Abstrak
Tujuan dari artikel ini adalah untuk mengetahui bagaimana keselarasan antara era financial technology bila disandingkan dengan prinsip islam secara konsep dan hukum di Indonesia. Financial technology berupaya untuk memudahkan manusia dalam memenuhi kebutuhan yang terus meningkat, mobilisasi manusia yang semakin cepat, serta kesibukan manusia yang selalu bertambah. Metode yang digunakan dalam penulisan artikel ini adalah tinjauan kritis terhadap fenomena berkembangnya era financial technology di Indonesia sebagai negara berkembang yang mengadopsi era financial technology dari negara maju. Literatur yang digunakan dalam makalah ini berasal dari jurnal ilmiah baik secara nasional maupun internasional dan ditunjang dengan buku-buku ilmiah dari berbagai ilmuwan. Artikel ini diharapkan dapat memberikan tambahan pengetahuan, menjadi jalan pembuka untuk penelitian selanjutnya, serta dijadikan sebagai panduan dalam menjalankan bisnis di berbagai level yang mempertimbangkan untuk menggunakan financial technology .
\end{abstract}

Kata Kunci: financial technology, islamic perspective, regulasi.

\begin{abstract}
The purpose of this article is to find out how the harmony between the era of financial technology when compared with Islamic principles in concept and law in Indonesia. Financial technology strives to make it easier for humans to meet their ever-increasing needs, faster mobilization of people, and a growing human activity. The method used in writing this article is a critical review of the phenomenon of the development of the era of financial technology in Indonesia as a developing country that adopted the era of financial technology from developed countries. The literature used in this paper comes from scientific journals both nationally and internationally and is supported by scientific books from various scientists. This article is expected to provide additional knowledge, be an opening path for further research, and serve as a guide in conducting business at various levels that consider using financial technology.
\end{abstract}

Keywords: financial technology, islamic perspective, regulation 


\section{PENDAHULUAN}

Tahun 2019 adalah tahun dimana segala aspek dalam kehidupan manusia telah tersentuh oleh teknologi. Kebutuhan yang terus meningkat, mobilisasi manusia yang semakin cepat, serta kesibukan manusia yang selalu bertambah memaksa adanya fasilitias yang dapat memenuhi itu semua. Istilah financial technologi telah lebih dulu digunakan di negara-negara maju didunia, dan Indonesia mulai mengadopsi financial technology beberapa tahun ini. Adopsi ini mengikuti kebutuhan dan kebiasaan manusia yang membutuhkan kemudahan dan 'shortcut' untuk berbagai urusan. Dengan mempertimbangkan cepatnya berkembangnya teknologi di Indonesia, tidak mustahil bila semua dapat di wujudkan. Istilah 'uang tidak bisa membeli waktu' tampaknya secara konotatif tidak seberapa berlaku lagi sekarang. Berbagai kemudahan teknologi tentu membawa konsekuensi dalam hal fasilitas yang harus dipersiapkan. Termasuk berapa biaya yang harus dikeluarkan oleh pemerintah atau pelaku bisnis untuk mewujudkan kemudahan dalam teknologi. Menurut Peraturan Otoritas Jasa Keuangan Nomor 77/POJK.01/Tahun 2016 Mengenai Layanan Teknologi Informasi yang dirilis pada 28 Desember 2016, jumlah perusahaan yang menawarkan layanan sampai 4 September, jumlah perusahaan P2P landing yang terdaftar atau mengantongi izin dan mendaftarkan perusahaannya mencapai 40 entitas, tentu setiap tahun dapat bertambah. Konsep financial technology dapat memudahkan apa yang dirasa sulit dan memakan banyak waktu, namun yang juga harus diperhatikan adalah apakah masuknya era financial technology ke dalam bisnis sesuai dengan budaya Indonesia yang memiliki mayoritas agama islam. Islam memiliki peraturan dan regulasi dalam menjalankan bisnis yang baik untuk mencapai kemaslahatan bersama. Indonesia juga memiliki era baru dalam prinsip bisnis, yaitu syariah. makalah ini akan membahas keselarasan yang terjadi di Indonesia menganai masuknya financial technology dan prinsip syariah secara bersama-sama.

\section{LANDASAN TEORI}

\section{Financial Technology: Konvensional}

Secara umum, financial technology dapat diartikan sebagai sebuah inovasi teknologi dalam layanan transaksi keuangan. Menurut peraturan Bank Indonesia Nomor 19/12/PBI/2017 tentang penyelenggaraan teknologi finansial, teknologi finansial adalah penggunaan teknologi dalam sistem keuangan yang menghasilkan produk, layanan, teknologi, dan/atau model bisnis baru serta dapat berdampak pada stabilitas moneter, stabilitas sistem keuangan, dan/atau 
efisiensi, kelancaran, keamanan, dan keandalan sistem pembayaran. Lebih lanjut menurut peraturan Bank Indonesia Nomor 19/12/PBI/2017 tentang penyelenggaraan teknologi finansial, tujuan dilaksanakan teknologi finansial adalah untuk mendorong inovasi di bidang keuangan dengan menerapkan perlindungan konsumen serta manajemen resiko dan kehati-hatian guna tetap menjaga stabilitas moneter, stabilitas sistem keuangan, dan sistem pembayaran yang efisien, lancar, aman, dan andal. Ruang lingkup dalam teknologi finansial yang wajib diikuti oleh entitas bisnis adalah mulai dari pendaftaran, regulatory sandbox, perizinan dan persetujuan, hingga pemantauan dan pengawasan.

Carney (2016) menjabarkan teknologi keuangan berawal dari sektor keuangan dalam perekonomian yang menjadi sektor kunci dan terus berkembang sesuai dengan kebutuhan masyarakat. Teknologi keuangan tidak hanya diterapkan di negara maju saja, tetapi juga mulai muncul dan tumbuh di negara berkembang, seperti Indonesia. Financial technology membawa harapan baru bagi kemudahan dalam berbagai macam transaksi keuangan dalam berbagai sektor.

\section{Financial Technology: Syariah}

Konsep dasar Islam adalah tauhid atau meng-Esa-kan Allah. Tauhid di bidang ekonomi adalah menempatkan Allah sebagai Sang Maha Pemilik yang selalu hadir dalam tiap nafas kehidupan manusia (Jairin, 2019). Islam mengatur berbagai hal dalam sendi kehidupan manusia, termasuk dalam berbisnis. Al-Qur'an dan hadis yang menyebut dan menjelaskan aturan dalam perdagangan sebanyak 20 penjabaran tentang perdagangan yang diulang sebanyak 720 kali.

Menurut Agustianto (2004) al-Qur'an mengatur delapan prinsip mengenai perdagangan agar tercipta kemaslahatan bersama, yaitu: Pertama, setiap melakukan transaksi dalam perdagangan, wajib adanya sikap saling ridha antara produsen dan konsumen, sehingga kedua belah pihak tidak merasa dirugikan dan dizalimi; kedua, menjunjung tinggi prinsip keadilan, keseimbangan dalam takaran, ukuran mata uang, dan pembagian keuntungan; ketiga, diharamkannya riba'; keempat, kasih sayang dan tolong menolong sesama bersaudara secara universal; kelima, tidak melakukan segala macam kegiatan investasi keuangan pada usaha yang diharamkan; keenam, perdagangan harus menghindari praktik spekulasi, gharar, tadlis, dan maysir; ketujuh, perdagangan tidak boleh melupakan ibadah sholat dan zakat serta selalu mengingat Allah; dan kedelapan, wajib adanya pencatatan baik itu tunai, hutang-piutang. 
Berbagai negara berkembang mulai mengadopsi konsep financial technology, baik secara penuh ataupun sebagian, seperti di Tanzania. Terdapat penelitian yang dilakukan oleh Sulayman di Tanzania. Menurut Sulayman (2015) Tanzania merupakan negara yang mengalami perubahan pertumbuhan yang bisa dikatakan secara mendadak dalam bidang industri keuangan islam selama beberapa waktu terakhir. Namun sayangnya, kemajuan dalam bidang industri keuangan islam tidak diimbangi dengan kemajuan dalam hal fasilitas teknologi yang dapat menampung perubahan tersebut. Bila kelemahan itu terus dibiarkan, maka akan membuat semakin buruknya keadaan sosial ekonomi masyarakat. Lebih lanjut Sulayman menambahkan, untuk mengimbangi peningkatan industri keuangan islam dan agar dapat bertahan, maka perlu dilakukan beberapa langkah, yaitu: mempromosikan literasi keuangan Islami, mengambil tindakan pada waktunya, mempertahankan nilai-nilai etika Islami, memanfaatkan upaya pembangunan sosial-ekonomi di wilayah tersebut, meningkatkan investasi ekonomi di tingkat makro.

Menurut Salman dan Nawaz (2018), memang terdapat celah dan perbedaan yang luas antara sistem konvensional dan sistem syariah dalam berbagai bidang. Masyarakat cenderung lebih mempercayakan keuangan mereka pada lembaga keuangan dengan landasan syariah. Prinsip dasar dalam menjalankan transaksi keuangan adalah sesuai dengan al-quran dan al-hadis. Pada dasarnya akad yang terdapat pada fintech (muamalah) selama tidak bertentangan dengan prinsip syariah maka hal tersebut diperbolehkan (Al-ashlu fil muamalah al ibahah). Selain itu fintech merujuk pada salah satu asas muamalah lainnya yaitu an-taradhin yang memilik arti saling ridho diantara keduanya. Perlu diperhatikan dengan cermat pula unsur-unsur syariah, sebagaimana yang disampaikan al-Ghazali dalam hifz ad-din, hifz-an-nafs, hifz al-aql, hifz-annasl, dan hifzal-mal. Dengan adanya fintech ini adalah sebagai upaya memudahkan setiap orang dalam bertransaksi dan investasi berdasarkan prinsip syariah. Beberapa prinsip syariah ini mengatur bagaimana proses sampai dengan tujuan akhir,dapat dilakukan dengan baik dan benar.

Saat ini kendala yang dihadapi oleh fintech berbasis syariah, yaitu terkait perbedaan akad yang digunakan. Beberapa jenis fintech yang telah diatur kesyariahannya adalah jenis Peer to Peer Lending (pinjaman berbasis teknologi), uang elektronik (e-Money), dan gerbang pembayaran (payment gateway). Hukum syariah yang mengatur financial technology belum memiliki kepastian hukumnya beberapa jenis fintech seperticrowdfunding, market 
aggregator, risk \&investment management belum memiliki fatwa syariahnya. Maka perlu adanya kepastian hukum syariah yang harus selaras dengan dinamika perkembangan teknologi.

Menurut data otoritas jasa keuangan, sudah terdapat 106 perusahaan yang memperoleh izin untuk mendirikan perusahaan berbasis financial technology baik secara konvensional maupun syariah, seperti yang dapat dijabarkan dalam tabel 1 dibawah ini:

Tabel 1: perusahaan financial technology lending berizin dan terdaftar di otoritas jasa keuangan sampai bulan April 2019

\begin{tabular}{|c|l|l|}
\hline No. & \multicolumn{1}{|c|}{ Nama Perusahaan } & \multicolumn{1}{|c|}{ Jenis } \\
\hline 1 & PT Pasar Dana Pinjaman & Konvensional \\
\hline 2 & $\begin{array}{l}\text { PT Lunaria Annua } \\
\text { Teknologi }\end{array}$ & Konvensional \\
\hline 3 & PT Amartha Mikro Fintek & Konvensional \\
\hline 4 & PT Investree Radhika Jaya & $\begin{array}{l}\text { Konvensional } \\
\text { dan Syariah }\end{array}$ \\
\hline 5 & $\begin{array}{l}\text { PT Mitrausaha Indonesia } \\
\text { Grup }\end{array}$ & Konvensional \\
\hline 6 & $\begin{array}{l}\text { PT Pendanaan Teknologi } \\
\text { Nusa Konvensional }\end{array}$ \\
\hline 7 & $\begin{array}{l}\text { PT Simplefi Teknologi } \\
\text { Indonesia }\end{array}$ & Konvensional \\
\hline 8 & PT Aman Cermat Cepat & Konvensional \\
\hline 9 & $\begin{array}{l}\text { PT Mediator Komunitas } \\
\text { Indonesia }\end{array}$ & Konvensional \\
\hline 10 & $\begin{array}{l}\text { PT Akseleran Keuangan } \\
\text { Inklusif Indonesia }\end{array}$ & Konvensional \\
\hline 11 & PT Digital Alpha Indonesia & Konvensional \\
\hline 12 & PT Indo Fin Tek & Konvensional \\
\hline 13 & PT Indonusa Bara Sejahtera & Konvensional \\
\hline 14 & $\begin{array}{l}\text { PT Fintegra Homido } \\
\text { Indonesia }\end{array}$ & Konvensional \\
\hline 15 & PT Sol Mitra Fintec & Konvensional \\
\hline 16 & $\begin{array}{l}\text { PT. Creative Mobile } \\
\text { Adventure }\end{array}$ & Konvensional \\
\hline 17 & PT Digital Tunai Kita & Konvensional \\
\hline 18 & $\begin{array}{l}\text { PT iGrow Resources } \\
\text { Indonesia }\end{array}$ & Konvensional \\
\hline 19 & $\begin{array}{l}\text { PT Cicil Solusi Mitra } \\
\text { Teknologi }\end{array}$ & Konvensional \\
\hline 20 & PT. Intekno Raya & Konvensional \\
\hline 21 & PT Kas Wagon Indonesia & Konvensional \\
\hline 22 & PT Esta Kapital Fintek & Konvensional \\
\hline
\end{tabular}




\begin{tabular}{|c|c|c|}
\hline 23 & PT Ammana Fintek Syariah & Syariah \\
\hline 24 & $\begin{array}{l}\text { PT Gradana Teknoruci } \\
\text { Indonesia }\end{array}$ & Konvensional \\
\hline 25 & PT Mapan Global Reksa & Konvensional \\
\hline 26 & $\begin{array}{l}\text { PT Aktivaku Investama } \\
\text { Teknologi }\end{array}$ & Konvensional \\
\hline 27 & PT Dana Kini Indonesia & Konvensional \\
\hline 28 & PT Oriente Mas Sejahtera & Konvensional \\
\hline 29 & $\begin{array}{lll}\text { PT } & \text { Digital } & \text { Synergy } \\
\text { Technology } & \end{array}$ & Konvensional \\
\hline 30 & $\begin{array}{lll}\text { PT Toko Modal } & \text { Mitra } \\
\text { Usaha } & & \\
\end{array}$ & Konvensional \\
\hline 31 & PT Artha Dana Teknologi & Konvensional \\
\hline 32 & $\begin{array}{l}\text { PT FinAccel Digital } \\
\text { Indonesia }\end{array}$ & Konvensional \\
\hline 33 & $\begin{array}{l}\text { PT Mekar Investama } \\
\text { Sampoerna }\end{array}$ & Konvensional \\
\hline 34 & PT Dana Pinjaman Inklusif & Konvensional \\
\hline 35 & PT Perlu fintech Indonesia & Konvensional \\
\hline 36 & PT Kredit Pintar Indonesia & Konvensional \\
\hline 37 & PT Fintek Digital Indonesia & Konvensional \\
\hline 38 & $\begin{array}{l}\text { PT Crowde Membangun } \\
\text { Bangsa }\end{array}$ & Konvensional \\
\hline 39 & PT Kredit Plus Teknologi & Konvensional \\
\hline 40 & $\begin{array}{l}\text { PT Tanifund } \quad \text { Madani } \\
\text { Indonesia }\end{array}$ & Konvensional \\
\hline 41 & PT Mulia Inovasi Digital & Konvensional \\
\hline 42 & $\begin{array}{l}\text { PT Bursa } \\
\text { Indonesia }\end{array}$ & Konvensional \\
\hline 43 & $\begin{array}{l}\text { PT Semesta Gerakan } \\
\text { Persada }\end{array}$ & Konvensional \\
\hline 44 & PT Tri Digi Fin & Konvensional \\
\hline 45 & PT Grha Dena Bersama & Konvensional \\
\hline 46 & PT Glotech Prima Vista & Konvensional \\
\hline 47 & $\begin{array}{l}\text { PT Kredit Utama fintech } \\
\text { Indonesia }\end{array}$ & Konvensional \\
\hline 48 & $\begin{array}{l}\text { PT Layanan Keuangan } \\
\text { Berbagi }\end{array}$ & Konvensional \\
\hline 49 & PT Digital Micro Indonesia & Konvensional \\
\hline 50 & PT Artha Permata Makmur & Konvensional \\
\hline 51 & PT Seva Kreasi Digital & Konvensional \\
\hline 52 & PT Dana Syariah Indonesia & Syariah \\
\hline 53 & PT Solusi Finansial Inklus if & Konvensional \\
\hline 54 & PT Modal Rakyat Indonesia & Konvensional \\
\hline 55 & PT Kawan Cicil Teknologi & Konvensional \\
\hline
\end{tabular}




\begin{tabular}{|c|c|c|}
\hline & Utama & \\
\hline 56 & PT Satustop Finansial Solusi & Konvensional \\
\hline 57 & PT Alfa Finance Indonesia & Konvensional \\
\hline 58 & $\begin{array}{l}\text { PT Uangme } \\
\text { Indonesia }\end{array}$ & Konvensional \\
\hline 59 & $\begin{array}{l}\text { PT Stanford } \\
\text { Indonesia }\end{array}$ & Konvensional \\
\hline 60 & $\begin{array}{l}\text { PT Kuai Kuai } \\
\text { Indonesia }\end{array}$ & Konvensional \\
\hline 61 & $\begin{array}{ll}\text { PT Finansial } & \text { Integrasi } \\
\text { Teknologi } & \end{array}$ & Konvensional \\
\hline 62 & $\begin{array}{ll}\text { PT Julo Teknologi } \\
\text { Indonesia }\end{array}$ & Konvensional \\
\hline 63 & $\begin{array}{l}\text { PT Indonesia Fintopia } \\
\text { Technology }\end{array}$ & Konvensional \\
\hline 64 & $\begin{array}{lll}\text { PT Astra Welab Digital } \\
\text { Artha }\end{array}$ & Konvensional \\
\hline 65 & $\begin{array}{l}\text { PT Finlink } \\
\text { Indonesia }\end{array}$ & Konvensional \\
\hline 66 & PT Pohon Dana Indonesia & Konvensional \\
\hline 67 & PT Inclusive Finance Group & Konvensional \\
\hline 68 & PT Pasar Dana Teknologi & Konvensional \\
\hline 69 & $\begin{array}{ll}\text { PT Trust } & \text { Teknologi } \\
\text { Finansial } & \end{array}$ & Konvensional \\
\hline 70 & $\begin{array}{l}\text { PT Adiwisista } \\
\text { Teknologi }\end{array}$ & Konvensional \\
\hline 71 & $\begin{array}{ll}\text { PT Pinduit } & \text { Teknologi } \\
\text { Indonesia } & \end{array}$ & Konvensional \\
\hline 72 & PT Pinjam Memijam Global & Konvensional \\
\hline 73 & PT Dana Aguna Nusantara & Konvensional \\
\hline 74 & PT Sejahtera Sama Kita & Konvensional \\
\hline 75 & $\begin{array}{l}\text { PT Minitech } \\
\text { Indonesia }\end{array}$ & Konvensional \\
\hline 76 & $\begin{array}{lll}\text { PT } & \text { Nusantara } & \text { Digital } \\
\text { Techno } & & \\
\end{array}$ & Konvensional \\
\hline 77 & PT Tujuh Mandiri Sejahtera & Konvensional \\
\hline 78 & $\begin{array}{ll}\text { PT Abadi } & \text { Sejahtera } \\
\text { Investindo } & \\
\end{array}$ & Konvensional \\
\hline 79 & $\begin{array}{l}\text { PT Pembiayaan Digital } \\
\text { Indonesia }\end{array}$ & Konvensional \\
\hline 80 & PT Indo Fintek Digital & Konvensional \\
\hline 81 & PT Pintar Inovasi Digital & Konvensional \\
\hline 82 & $\begin{array}{l}\text { PT Danafix Online } \\
\text { Indonesia }\end{array}$ & Konvensional \\
\hline 83 & PT $\quad$ Lumbung & Konvensional \\
\hline
\end{tabular}




\begin{tabular}{|c|c|c|}
\hline & Indonesia & \\
\hline 84 & $\begin{array}{lll}\text { PT } & \text { Lampung } & \text { Berkah } \\
\text { Financial } & \text { Teknologi } & \end{array}$ & Konvensional \\
\hline 85 & $\begin{array}{l}\text { PT Solusi } \quad \text { Teknologi } \\
\text { Finansial }\end{array}$ & Konvensional \\
\hline 86 & PT Dana Bagus Indonesia & Konvensional \\
\hline 87 & PT Lentera Dana Nusantara & Konvensional \\
\hline 88 & $\begin{array}{l}\text { PT Investdana Fintek } \\
\text { Nusantara }\end{array}$ & Konvensional \\
\hline 89 & PT Unikas Indonesia Pasifik & Konvensional \\
\hline 90 & $\begin{array}{ll}\text { PT Teknologi } & \text { Merlin } \\
\text { Sejahtera } & \\
\end{array}$ & Konvensional \\
\hline 91 & PT Progo Puncak Group & Konvensional \\
\hline 92 & $\begin{array}{l}\text { PT Digital Bertahan } \\
\text { Indonesia }\end{array}$ & Konvensional \\
\hline 93 & $\begin{array}{ll}\text { PT Kreditku Teknologi } \\
\text { Indonesia }\end{array}$ & Konvensional \\
\hline 94 & PT Berkah Kelola Dana & Konvensional \\
\hline 95 & PT Kreasi Anak Indonesia & Konvensional \\
\hline 96 & $\begin{array}{l}\text { PT Anantara Digital } \\
\text { Indonesia }\end{array}$ & Konvensional \\
\hline 97 & $\begin{array}{l}\text { PT Komunal Finansial } \\
\text { Indonesia }\end{array}$ & Konvensional \\
\hline 98 & $\begin{array}{l}\text { PT Newline fintech } \\
\text { Indonesia }\end{array}$ & Konvensional \\
\hline 99 & PT Danakoo Mitra Artha & Syariah \\
\hline 100 & PT Idana Solusi Sejahtera & Konvensional \\
\hline 101 & $\begin{array}{ll}\text { PT Berdayakan Usaha } \\
\text { Indonesia }\end{array}$ & Konvensional \\
\hline 102 & PT Empat Kali Indonesia & Konvensional \\
\hline 103 & PT Akur Dana Abadi & Konvensional \\
\hline 104 & $\begin{array}{l}\text { PT Pinjaman Kemakmuran } \\
\text { Rakyat }\end{array}$ & Konvensional \\
\hline 105 & PT Sinergi Mitra Finansial & Konvensional \\
\hline 106 & $\begin{array}{l}\text { PT Harapan fintech } \\
\text { Indonesia }\end{array}$ & Konvensional \\
\hline
\end{tabular}

Sumber: Otoritas Jasa Keuangan, perusahaan fintech lending berizin dan terdaftar di OJK 2019 (data diolah)

\section{Landasan Hukum di Indonesia}

Landasan hukum mengenai pelaksanaan teknologi finansial di Indonesia diatur dalam Peraturan Bank Indonesia Nomor 19/12/PBI/2017 Tentang Penyelenggaraan Teknologi 
Finansial. Menurut peraturan tersebut, adanya undang-undang yang mengatur tentang teknologi finansial berlandaskan pada perkembangan teknologi dan sistem informasi yang terus melahirkan berbagai inovasi, khususnya yang berkaitan dengan teknologi finansial untuk memenuhi berbagai kebutuhan masyarakat dan dapat membawa manfaat bagi masyarakat. Teknologi finansial wajib selalu dimonitor dan dan dikembangkan untuk mendukung terciptanya stabilitas moneter, stabilitas sistem keuangan, serta sistem pembayaran yang efisien, lancar, dan andal. Bank Indonesia sebagai bank sentral wajib selalu memberi respon terhadap kemajuan teknologi agar sinkron, harmonis, dan selalu terintegrasi dengan kebijakan Bank Indonesia lainnya seperti pelaksanaan pemrosesan transaksi pembayaran dan gerbang pembayaran nasional (national Payment Gateway) serta perlu dikoordinasikan dengan otoritas terkait.

Landasan hukum lain mengenai teknologi finansial tertuang dalam Peraturan Otoritas Jasa Keuangan Republik Indonesia Nomor 13/POJK.02/2018 Mengenai Inovasi Keuangan Digital di Sektor Jasa Keuangan. Menurut Peraturan Otoritas Jasa Keuangan Republik Indonesia nomor 13/POJK.02/2018 mengenai inovasi keuangan digital di sektor jasa keuangan, perkembangan teknologi inovasi keuangan tidak dapat diabaikan begitu saja dan harus dikelola dengan baik agar dapat memberikan manfaat sebesar-besarnya untuk kepentingan masyarakat. Inovasi keuangan digitak juga perlu diarahkan agar dapat menghasilkan inovasi keuangan digital yang bertanggung jawab, aman, mengedepankan perlindungan konsumen dan memiliki risiko yang terkelola dengan baik. Hal ini selaras dengan pertimbangan peraturan Bank Indonesia Nomor 19/12/PBI/2017 tentang penyelenggaraan teknologi finansial.

Fatwa Dewan Standar Majelis Ulama Indonesia Nomor 117/DSN-MUI/II/2018 Mengenai Layanan Pembiayaan Berbasis Teknologi Informasi Berdasarkan Prinsip Syariah. menurut menurut Sahroni (2018) didalam Fatwa Dewan Standar Majelis Ulama Indonesia Nomor 117/DSN-MUI/I/2018 Mengenai Layanan Pembiayaan Berbasis Teknologi Informasi Berdasarkan Prinsip Syariah, terdapat tiga parameter produk ekonomi dapat dikategorikan sesuai dengan syariah, yaitu: pertama, terbebas dari transaksi yang dilarang; kedua, produk sesuai dengan akad atau transaksi syariah; dan ketiga, wajib menjaga adab-adab (akhlak) islam dalam bermuamalah.

METODE PENELITIAN 
Metode yang digunakan dalam penulisan artikel ini adalah tinjauan kritis terhadap fenomena berkembangnya era financial technology di Indonesia sebagai negara berkembang yang mengadopsi era financial technology dari negara maju. Fenomena tersebut akan disandingkan dengan hukum dan regulasi dalam prinsip bisnis islam yang tertera didalam quran dan hadis apakah sesuai, bertentangan, atau bertolak belakang. Literatur yang digunakan dalam makalah ini berasal dari jurnal ilmiah baik secara nasional maupun internasional dan ditunjang dengan buku-buku ilmiah dari berbagai ahli.

\section{PEMBAHASAN}

Teknologi keuangan merupakan konsep baru untuk memudahkan konsumen dan produsen dalam bertransaksi keuangan tanpa harus bertemu secara langsung setiap saat. Menurut Meifang et al (2018), hadirnya internet dalam transaksi keuangan dapat memberikan keunggulan aksesbilitas dan jangkauan akses. Lebih lanjut menurut Meifang, salah satu contoh inovasi dalam bidang teknologi pembayaran keuangan adalah e-commerce. Beberapa faktor yang menunjang pertumbuhan peningkatan pertumbuhan e-commerce adalah pengaplikasian IOT dan cloud computing dalam sebuah rantai produksi, logistik, dan transportasi. Dukungan internet mobile juga memungkinkan konsumen melakukan transaksi dimanapun dan kapanpun. Menurut Chandra (2018) yang dikutip dari situs detikfinance.com, inovasi keuangan perlu diarahkan supaya melahirkan inovasi keuangan digitak yang responsibel, safety, dan mengutamakan perlindungan konsumen serta memiliki risiko yang dapat dikelola dengan baik.

Teknologi keuangan memang dapat memberikan kemudahan dalam berbagai hal, namun teknologi keuangan juga kadang memberikan beberapa kelemahan. Seperti yang dijabarkan oleh Korwatanasakul (2018). Menurut Korwatanasakul, keberadaan teknologi dapat menjadi penghalang bagi orang yang memiliki kekurangan fisik (penglihatan). Korwatanasakul melakukan eksperimen pada 40 orang yang menderita kelemahan penglihatan. Kendala desain fisik penggunaan teknologi ATM sulit untuk dihadapi. Sangat sulit untuk mengakses layanan keuangan seperti pembayaran, transfer, maupun deposito. Hal ini karena banyak desain teknologi keuangan yang ada masih tidak mendukung bagi orang yang mengalami keterbatasan penglihatan. Kelemahan lain adalah adanya inklusi keuangan. Bansal (2014) melakukan penelitian di India. Sebagian besar penduduk India tidak memiliki akses keuangan yang baik. karena tidak adanya produk keuangan yang sesuai dengan tingkat pendapatan masyarakat menengah kebawah. Lebih lanjut menurut Bansal, salah satu upaya untuk menjembatani jurang 
kesenjangan ekonomi dengan menggunakan teknologi informasi dan komunikasi. RBI dan beberapa lembaga keuangan lainnya, telah memanfaatkan TIK untuk meningkatkan inklusi keuangan di daerah pedesaan. Mobile banking dan ATM merupakan salah satu teknologi yang digunakan peningkatan inklusi keuangan, terutama pada area yang tidak terjangkau layanan perbankan. Sebenarnya, adanya teknologi keuangan dapat memberika manfaat bila dikembangkan dengan cara yang benar. Menurut Ozili (2017), keuangan digital dapat memberikan keuntungan untuk berbagai pihak, yaitu pengguna layanan keuangan, penyedia layanan digital, serta pemerintahan dalam bidang ekonomi.

Dewan Standar Nasional Majelis Ulama Indonesia telah mengeluarkan fatwa terkait layanan pembiyaan berbasis teknologi informasi berdasarkan prinsip syariah. dikeluarkannya fatwa tersebut dengan didukung adanya beberapa ayat quran, hadis, dan kaidah fikih.

\section{$\underline{\text { Ayat Quran }}$}

'hai orang-orang yang beriman! Tunaikanlah akad-akad itu..' QS. AlMaidah (5):1

'dan tunaikanlah janji-janji itu. Sesungguhnya janji itu akan dimintai pertanggungjawaban...' QS. Al-Isra (17):34

'hai orang-orang yang beriman! Janganlah kalian memakan (mengambil) harta orang lain secara batil, kecuali jika berupa perdagangan yang diambil atas sukarela di antara kalian..' QS. An-Nisa (4): 29

\section{Hadis Nabi Muhammad SAW}

Hadis Nabi s.a.w. riwayat al-Tirmidzi dari kakeknya 'Amr bin 'Auf alMuzani, dan riwayat al-Hakim dari kakeknya Katsir bin Abdillah bin amr bin 'Aun r.a.:

Shulh (penyelesaian perkara melalui musyawarah untuk mufakat) dapat dilakukan di antara kaum muslimin kecuali shulh yang mengharamkan yang halal atau menghalalkan yang haram; dan kaum muslimin terikat dengan syarat-syarat yang diberlakukan di antara 
mereka kecuali syarat yang mengharamkan yang halal atau menghalalkan yang haram,

Hadis Nabi saw. riwayat Muslim, dari 'Aisyah dan dari Tsabit dari Anas:

"Kalian lebih mengetahui urusan dunia kalian'

\section{$\underline{\text { Kaidah Fikih }}$}

"Pada dasarnya, segala bentuk muamalat diperbolehkan kecuali ada dalil yang mengharamkannya"

" Segala dharar (bahaya/kerugian) harus dihilangkan"

"Segala dharar (bahaya/kerugian) harus dicegah sebisa mungkin"

"Sesuatu yang berlaku berdasarkan adat kebiasaan sama dengan sesuatu

yang berlaku berdasarksn syara' (selama tidak bertentangan dengan

syariat)"

"Adat kebiasaan dapat ditetapkan sebagai hukum”

"Ketetapan hukum tergantung pada ada tidaknya 'illah”

"Kebijakan pemimpin terhadap rakyat harus mengikuti (mengacu/berpihak ) kepada kemaslahatan (masyarakat) "

"Di mana terdapat kemaslahatan, di sana terdapat hukum Allah"

Dewan Standar Nasional Majelis Ulama Indonesia menerbitkan fatwa tersebut karena mempertimbangkan beberapa hal, yaitu: 1) semakin berkembangnya teknologi dan semakin cepatnya akses yang dibutuhkan oleh pelaku usaha skala mikro, kecil, dan menengah; serta 2) masyarakat memerlukan penjelasan terkait ketentuan dan regulasi hukum terkait pembiayaan berbasis teknologi.

Akad dan pertemuan antara produsen dan konsumen (penjual dan pembeli) di satu tempat/majelis dalam setiap bertransaksi memang salah satu syarat sah yang harus dipenuhi. Namun, pada konsep financial technology, kedua aspek tersebut dihilangkan. Hal ini disebabkan karena pergerakan manusia yang sangat tinggi, waktu yang semakin terbatas, dan transaksi yang 
harus tetap terpenuhi membuat akad dan pertemuan bukan menjadi kewajiban. Financial technology mampu mengganti kedua aspek tersebut dengan perjanjuan dan pertemuan secara online dan mobile.

Fatwa Dewan Standar Nasional Majelis Ulama Indonesia dalam salah satu paragraf penjelas telah menjabarkan, yang dimaksud dengan sahr majelis dalam setiap akad seperti yang telah kami jelaskan bukanlah keberadaan kedua pihak yang bertransaksi dalam satu tempat. Sebab terkadang tempat kedua pihak itu berbeda ketika ada perantara yang menghubgngkan keduanya. Seperti transaksi via telepon, radiogram atau via surat. Maksud satu majelis adalah satu Zaman atau waktu yang di dalamnya kedua belah pihak melakukan transaksi. Maka majelis akad adalah kondisi yang di dalamnya kedua belah pihak melakukan transaksi. Dari hal ini para ahli fiqh berkesimpulan: "sungguh majelis itu mengumpulkan beberapa hal yang terpisah. Berdasarkan keterangan ini, maka majelis akad dalam perbincangan via telepon atau radiogram adalah waktu tersambungnya kedua belah pihak selama pembicaraan masih terkait akad. Oleh sebab itu, bila pembicaraan kedua belah sudah beralih ke hal lain, maka majelis akad berakhir.

Lebih lanjut dalam keputusan Dewan Standar Nasional Majelis Ulama Indonesia menjelaskan, Layanan Pembiayaan Berbasis Teknologi Informasi Berdasarkan Prinsip Syariah adalah penyelenggaraan layanan jasa keuangan berdasarkan prinsip syariah yang mempertemukan atau menghubungkan Pemberi Pembiayaan dengan Penerima Pembiayaan dalam rangka melakukan akad pembiayaan melalui sistem elektronik dengan menggunakan jaringan internet.

Menurut Yarli (2018), Dinamika dan berbagai kendala pemikiran yang dihadapi oleh financial technology syariah adalah adanya beda akad yang dipakai dalam sebuah entitas berbasis syariah. Menurut pekerti et al (2018), akad ijab qabul dalam sebuah perjanjian jual beli dapat dilaksanakan dengan ucapan, tulisan atau isyarat bagi mereka yang tidak mampu berbicara atau menulis. Bahkan dapat dilakukan dengan perbuata yang menunjukkan aspek rela antara kedua belah pihal untuk mengadakan sebuah perjanjian yang umumnya dikenal dengan al mu'athah. Sebenarnya, didalam Al-Qur'an tidak mengatur secara teknik dan detail apa saja penggunaan kata yang digunakan dalam sebuah ijab qabul jual beli. Ijab qabul jual beli dapat dilakukan menurut kebiasaan sepanjang tidak bertolak belakang denga syara'. 
Menurut Mohammed et al (2015), perlu untuk diadakannya standar akuntansi islam dalam pelaporan lembaga keuangan islam. lebih lanjut menurut Mohammed et al, selama ini masih belum ada standar akuntansi khusus untukk lembaga keuangan islam seperti haknya AAOIFI, hal ini dapat menimbulkan kendala teknis maupun non teknis dikemudian hari. Menurut Alsmadi dan Zarour (2014), terkadang ada hambatan teknis dapat terjadi dalam proses pengaplikasian peraturan syariah pada bidang-bidang layanan keuangan. Penelitian lain dilakukan oleh Zaina et al (2015). Zaina melakukan penelitian pada 37 pasar institusi keuangan islam di Malaysia pada 2012. Hasil yang didapat adalah prinsip-prinsip dan nilai-nilai Islam terkait kebijakan pasar mendapat perhatian paling sedikit. Ini menunjukkan bahwa lembaga keuangan Islam belum secara strategis memasukkan prinsip-prinsip dan nilai-nilai Islam ke dalam kebijakan yang terkait dengan dimensi pasar.

\section{PENUTUP}

Hukum yang mengatur mengenai pembiayaan teknologi keuangan secara konvensional diatur dalam Peraturan Bank Indonesia Nomor 19/12/PBI/2017 Tentang Penyelenggaraan Teknologi Finansial, Peraturan Otoritas Jasa Keuangan Republik Indonesia Nomor 13/POJK.02/2018 Mengenai Inovasi Keuangan Digital di Sektor Jasa Keuangan. Hukum yang mengatur mengenai pembiayaan teknologi keuangan secara syariah tertuang didalam Fatwa Dewan Standar Majelis Ulama Indonesia Nomor 117/DSN-MUI/II/2018 Mengenai Layanan Pembiayaan Berbasis Teknologi Informasi Berdasarkan Prinsip Syariah. Teknologi keuangan pada dasarnya dapat mempermudah pergerakan manusia dalam bertransaksi keuangan. Konsep teknologi keuangan memanfaatkan jaringan internet dalam jaringan yang digunakan setiap saat oleh manusia. Teknologi keuangan meminimalisir atau bahkan menghilangkan regulasi dan syarat yang harus dipenuhi dalam transaksi keuangan, diantaranya adalah adanya perjanjian dan kewajiban bertemunya produsen dan konsumen. Konsep yang demikian cocok bila diterapkan dalam lingkup konvensional. berbeda dengan syariah yang pada dasarnya masih menganjurkan adanya akad dan pertemuan antara produsen dan konsumen. Dua aspek tersebut bertujuan untuk menghindari adanya potensi penipuan dan dirugikannya salah satu pihak. Namun, dalam maenghadapi masa depan, kedua aspek tersebut mulai disesuaikan kembali. Dewan Standar Nasional Majelis Ulama Indonesia membuat fatwa yang menjabarkan bahwa tidak harus dipenuhinya syarat adanyakad langsung dan bertemunya produsen dan konsumen. Dalam hal ini akad bisa digantikan dengan dokumen elektronik asalkan memenuhi syarat keseimbangan, 
kewajaran, dan keadilan sesuai syariah. Penulis berharap, adanya penelitian lanjut dimasa yang akan datang dan membahas mengenai teknologi keuangan dari sudut pandang yang lain. Penulis juga berharap, artikel ini dapat digunakan sebagai bahan referensi yang bersifat ilmiah baik dalam bidang akademik maupun non akademik.

\section{DAFTAR PUSTAKA}

Agustianto. (2004). Ekonomi Keuangan dan Perdagangan dalam Al-Qur'an.

Alsmadi, I., \& Zarour, M. (2015). Building an Islamic Financial Information System Based on Policy Managements. Journal of King Saud University Computer and Information Science, 364-375.

Bansal, S. (2014). Perspective of Technology in Achieving Financial Inclusion in Rural India. Procedia Economics and Finance, 472-480.

Carney, M. (2016). Enabling the fintech transformation: Revolution, Restoration, or Reformation. BoE Speech .

Chandra, A. A. (2018, September 01). https://finance.detik.com/moneter/d-4192994/ojkterbitkan-aturan-baru-soal- fintech -ini-isinya. Retrieved June 12, 2019, from https://finance.detik.com: https://finance.detik.com/moneter/d-4192994/ojk-terbitkanaturan-baru-soal- fintech -ini-isinya.

Fatwa Dewan Standar Majelis Ulama Indonesia Nomor 117/DSN-MUI/II/2018 Mengenai Layanan Pembiayaan Berbasis Teknologi Informasi Berdasarkan Prinsip Syariah. (2018). Indonesia.

Jairin, J. (2019). KONTRIBUSI PERBANKAN SYARIAH DALAM PENGEMBANGAN USAHA EKONOMI MIKRO DI BIMA. Indonesian Interdisciplinary Journal of Sharia Economics (IIJSE), 2(1), 47-73. https://doi.org/10.31538/iijse.v1 i3.316

Korwatanasakul, W. (2018). Factors Influencing Technology Adoption of People with Visual Impairment: Case Study of Financial Transactions Through an Automatic Teller Machine (ATM). Kasetsart Journal of Social Science, 1-6.

Meifang, Y., He, D., \& Zheng Xianrong, X. X. (2018). Impact of Payment Technology Innovations on the Traditional Financial Industry: A Focus on China. Journal of Technological Forecasting and Social Change, 199-2017.

Mohammed, N. F., Fahmi, F. M., \& Ahmad, A. E. (2015). The Influence of AAOIFI Accounting Standards in Reporting Islamic Financial Institutions in Malaysia. Procedia Economics and Finance, 418-424.

Ozili, P. K. (2018). Impact of Digital Finance on Financial Inclusion and Stability. Borsa Istanbul Review, 329-340. 
Pekerti, R. D., \& Herwiyanti, E. (2018). Transaksi Jual Beli Online dalam Perspektif Syariah Madzhab Asy-Syafi'i. Jurnal Ekonomi, Bisnis, dan Akuntansi (JEBA) Volume 20 Nomor 02 .

Peraturan Bank Indonesia Nomor 19/12/PBI/2017 Tentang Penyelenggaraan Teknologi Finansial. Indonesia.

Peraturan Otoritas Jasa Keuangan Nomor 77/POJK.01/Tahun 2016 Mengenai Layanan Teknologi Informasi. (2016). Indonesia.

Peraturan Otoritas Jasa Keuangan Republik Indonesia Nomor 13/POJK.02/2018 Mengenai Inovasi Keuangan Digital di Sektor Jasa Keuangan. Indonesia.

Sahroni, O. (2018). Fatwa Dewan Standar Majelis Ulama Indonesia Nomor 117/DSNMUI/II/2018 Mengenai Layanan Pembiayaan Berbasis Teknologi Informasi Berdasarkan Prinsip Syariah. Indonesia.

Salman, A., \& Nawaz, H. (2018). Islamic Financial System and Conventional Banking: A Comparison. Arab Economic and Business Journal, 155-167.

Sulayman, H. I. (2015). Growth and Sustaining of Islamic Finance Practice in the Financial System of Tanzania: Challenges and Prospects. Procedia Economics and Finance, 361366.

Yarli, D. (Juli-Desember 2018). Analisis Akad Tijarah pada Transaksi fintech Syariah dengan Pendekatan Maqashid. Jurnal Pemikiran Hukum dan Hukum Islam YUDISIA, Vol. 9 No. 2 .

Zain, M. M., Darus, F., \& Ramli, A. (2015). Islamic Ethical Practices and the Marketplace: vidence from Islamic Financial Institutions. Procedia Economics and Finance, 266-273. 